$\Phi=$ 离

\title{
Pseudomonas aeruginosa in otitis media
}

\author{
Jidda B. Umar ${ }^{1}$, Muhammad M. Ibrahim ${ }^{2}$, Isyaka M. Tom ${ }^{3}$, Askira M. Umoru ${ }^{1}$, Tijjani Isa ${ }^{2}$ \\ ${ }^{1}$ Department of Medical Laboratory Science, University of Maiduguri, Nigeria \\ ${ }^{2}$ Department of Microbiology University of Maiduguri, Nigeria \\ ${ }^{3}$ Department of Medical Microbiology, University of Maiduguri, Nigeria \\ *Corresponding author E-mail: mnistyle@yahoo.com
}

\begin{abstract}
Background: Over $50 \%$ of cases of otitis media are caused by bacteria and Pseudomonas aeruginosa is the most common aetiologic agent implicated in the pathology of the disease.

Objectives: This study is designed to examine the influence of Pseudomonas aeruginosa in otitis media disease, and further look at the susceptibility pattern of the organism to commonly prescribed antimicrobial drugs.

Methods: Eighty two (82) swab samples were randomly collected from otitis media patients attending the ENT clinic of the University of Maiduguri Teaching Hospital and cultured for bacterial recovery. Further biochemical tests were conducted. Antimicrobial susceptibility test was performed and susceptibility pattern recorded.

Results: Nineteen (19) samples yielded growth of Pseudomonas aeruginosa, which gives a recovery rate of $23.2 \%$. The rate was higher among males $(12.2 \%)$ than females $(11.0 \%)$. The rate of isolation was highest among patients of the age category of $0-14 \mathrm{yrs}(11.0 \%)$ and least among those of $>44 \mathrm{yrs}(2.0 \%)$. Isolates were highly sensitive to Ciprofloxacin, Ofloxacin and Peflacin but highly resistant to Nalidixic acid and Ampicillin.

Conclusions: The infection is highest among children whose immune competence is still developing and as such, it is recommended that treatment should be based on results obtained from in-vitro susceptibility test, and that combination therapy should be considered to forestall chances of emergence of drug resistance.
\end{abstract}

Keywords: Antimicrobial Susceptibility; Combination Therapy; Otitis Media; Pseudomonas Aeruginosa; Resistance.

\section{Introduction}

Otitis media is an inflammatory disease of mucosal lining of the middle ear. Recurrent Otitis media may cause damage to ossicles, facial nerve and cochlea, resulting in permanent hearing loss. It can be acute or chronic (Tahira et al. 2009). Acute otitis media infection develops on the basis of a viral upper respiratory tract infection which leads to the blockage of the eustachian tube and effusion in the middle ear. Such effusions may be contaminated by bacteria. The most common bacteria found in this case are Streptococcus pneumoniae, Haemophilus influenzae and Moraxella catarrhalis (Lieberthal et al. 2013).

Chronic suppurative otitis media (CSOM) involves a perforation on the tympanic membrane and active bacterial infection within the middle ear space for several weeks or more. There is associated draining of pus to the outside (otorrhea) or the purulence may be minimal enough to only be seen on examination with a binocular microscope. Hearing loss usually accompanies an untreated case of chronic suppurative otitis media.

Bacterial infection of the middle ear usually originates from an upper respiratory tract infection with the bacteria entering the auditory tube (eustachian tube), which is the principal portal of entry of pathogens to the ear (Atlas 1998). Most common micro organisms found in CSOM are Pseudomonas aeruginosa, Staphylococcus aureus, Proteus mirabilis, Klebsiella pneumoniae, Escherichia coli, Aspergillus spp and Candida spp, but these organisms vary across different geographical areas.
The Gram-negative bacterium, Pseudomonas aeruginosa, is an opportunistic pathogen that normally inhabits the soil and surfaces in aqueous environments. Its adaptability and high intrinsic antibiotic resistance enable it to survive in a wide range of other natural and artificial settings, including surfaces of medical facilities. Most Pseudomonas aeruginosa infections are often nosocomial, and nearly all are associated with compromised host defenses such as the case may be in neutropenia, severe burns, or cystic fibrosis (Lyczak et al. 2000). Therapeutic options are increasingly limited due to the continued emergence and spread of antimicrobial resistant strains; as a result, Pseudomonas aeruginosa infections demonstrate high morbidity and mortality.

This study is aimed at identifying the implication of Pseudomonas aeruginosa as an etiologic agent of otitis media, and to look at the sensitivity pattern of the organism to commonly prescribed antimicrobial agents.

\section{Materials and methods}

\subsection{Study area}

The study was conducted in Maiduguri, the capital of Borno state. The city is located in the northeastern part of Nigeria which lies within latitude $11.15^{\circ} \mathrm{N}$ and longitude $30.05^{\circ} \mathrm{E}$ in the sudanosahelian savanna zone with a dense population that are mostly crop farmers, fishermen, herdsmen and traders (Udo 1978). Based on the national census conducted in 2006, Borno state has a population of 4151193 (NPC 2006). 


\subsection{Sample population}

The target population for the study include in-patients and outpatients attending Ear, Nose and throat (ENT) Clinic of the University of Maiduguri Teaching Hospital. The hospital is a 530 bed facility serving a population of over 20 million in the Northeastern sub-region of Nigeria, comprising six states (Borno, Bauchi, Yobe, Adamawa, Taraba and Gombe) as well as a sizeable number across the borders of Cameroon, Chad and Niger Republic (Nafada et al. 2011).

\subsection{Sample collection and processing}

The study was conducted from February 2013 to June 2013 Eighty two (82) swab samples of ear discharge were collected aseptically at random from patients diagnosed with otitis media attending the ENT Clinic. Fourty seven samples were collected from males and thirty five collected from females. Samples collected were transported immediately to the Microbiology Laboratory for processing. Samples were plated on Blood agar, MacConkey agar and Chocolate agar for bacterial recovery.

\subsection{Identification and characterization of bacterial iso- late}

Identification and characterization of bacterial isolate was conducted according to methods described by Cowon \& Steel (2002). Swab samples collected were inoculated onto Blood agar plate MacConkey agar plate and Chocolate agar plates for 18 to 24hours at $37^{\circ} \mathrm{C}$. The Chocolate agar plates were incubated anaerobically in an anaerobic jar in the presence of $\sim 5 \% \mathrm{CO}_{2}$. Further biochemical tests conducted include Indole test, Catalase test, Oxidase test, Coagulase test, Urease test, TSI and Citrate Utilization test.

\subsection{Antimicrobial susceptibility test}

The Kirby-Bauer disk diffusion susceptibility test was used to determine the sensitivity or resistance of Pseudomonas aeruginosa isolates to various antimicrobial compounds. The isolates were grown on Mueller-Hinton agar in the presence of various antimicrobial impregnated filter paper disks. The presence or absence of growth around the disks is an indirect measure of the ability of that compound to inhibit the growth of the organism.

The choice of antimicrobials to be included in susceptibility tests depend on the pathogen, the specimen, range of locally available antimicrobials, and local prescribing policies (Bauer 1966).

The antimicrobial agents tested include; Ciprofloxacin $(10 \mu \mathrm{g})$, Streptomycin $(30 \mu \mathrm{g})$, Ceporex $(10 \mu \mathrm{g})$, Ofloxacin $(10 \mu \mathrm{g})$, Peflacin $(10 \mu \mathrm{g})$, Gentamycin $(10 \mu \mathrm{g})$, Augmentin $(30 \mu \mathrm{g})$, Septrin $(30 \mu \mathrm{g})$, Ampicillin $(30 \mu \mathrm{g})$, and Nalidixic acid $(30 \mu \mathrm{g})$. Resistance data were interpreted according to the Clinical and Laboratory Standards Institute (CLSI) guidelines (CLSI 2006).

\subsection{Analysis of result}

Data were presented as percentage rates and frequencies.

\subsection{Ethical issues}

Ethical clearance was obtained from the Research Ethics Committee of the University of Maiduguri Teaching Hospital before data and sample collection from patients.

\section{Results}

Nineteen samples yielded positive growth of Pseudomonas aeruginosa out of the eighty two samples collected. This gives a total recovery rate of $23.2 \%$, which was highest among males (12.2\%) compared to females $(11.0 \%)$ (Table 1$)$.
The age distribution of positive samples was highest among samples collected from patients in the $0-14 \mathrm{yrs}(11.0 \%)$ age category and least among patients of $>44 \mathrm{yrs}(2.4 \%)$ age category (Table 2 ). Antimicrobial susceptibility test shows that isolates were most sensitive/least resistant to Ciprofloxacin, Ofloxacin, and Peflacin (89.5\%/10.5\% respectively) while Nalidixic acid recorded the least sensitivity/highest resistance with a rate of $10.5 \% / 89.5 \%$ (Table 3).

Table 1: Percentage Rate of Isolation of Pseudomonas Aeruginosa among Otitis Media Patients

\begin{tabular}{cccc} 
Test Organism & \multicolumn{2}{c}{ Sex } & \multirow{2}{*}{ Total (\%) } \\
\hline Pseudomonas aeruginosa $)$ & Male (\%) & Female (\%) & \\
\hline Positive & $10(12.2)$ & $9(11.0)$ & $19(23.2)$ \\
Negative & $37(45.1)$ & $26(31.7)$ & $63(76.8)$ \\
Total & $47(57.3)$ & $35(42.7)$ & $82(100)$ \\
\hline
\end{tabular}

Table 2: Age Distribution of the Rate of Isolation of Pseudomonas Aeruginosa among Otitis Media Patients

\begin{tabular}{cccccc}
\hline $\begin{array}{c}\text { Test Organism } \\
\text { (Pseudomonas } \\
\text { aeruginosa) }\end{array}$ & $0-14$ & $15-29$ & $30-44$ & $>44$ & Total(\%) \\
\hline Positive & $9(11.0)$ & $4(4.9)$ & $4(4.9)$ & $2(2.4)$ & $19(23.2)$ \\
Negative & $24(29.3)$ & $21(25.6)$ & $13(15.8)$ & $5(6.1)$ & $63(76.8)$ \\
Total & $33(40.3)$ & $25(30.5)$ & $17(20.7)$ & $7(8.5)$ & $82(100)$ \\
\hline
\end{tabular}

Table 3: Antimicrobial Susceptibility Pattern of Pseudomonas Aeruginosa isolated from Otitis Media Patients

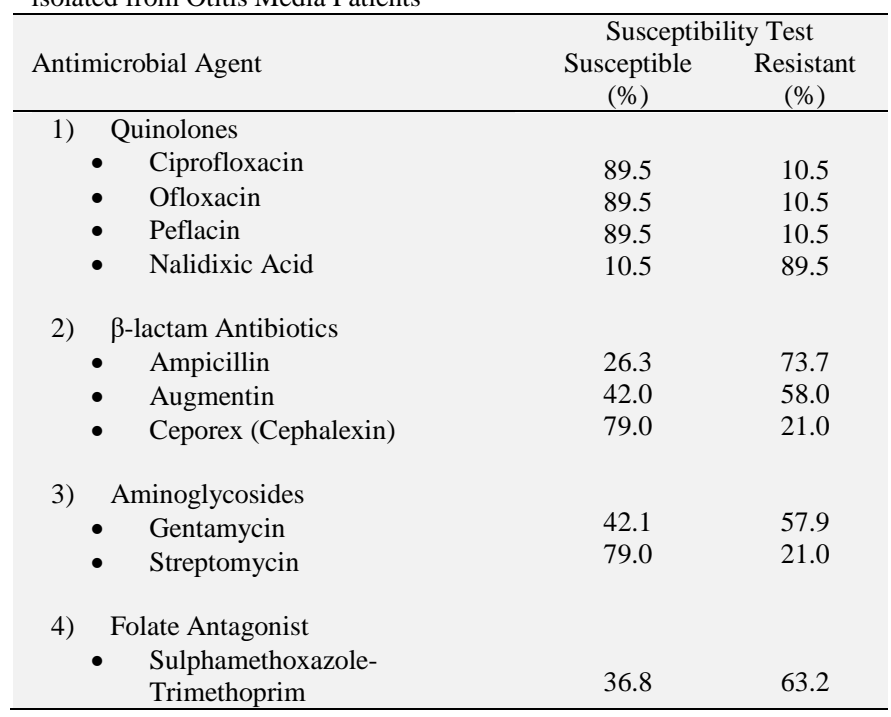

\section{Conclusion}

Different studies have been carried out establishing the significance of Streptococcus pneumoniae, Haemophilus influenzae, Pseudomonas aeruginosa, Moraxella catarrhalis, Proteus species, Staphylococcus aureus, Escherichia coli and Klebsiella spp in the aetiology of otitis media (Harold and Francis, 1992; Mackie and McCartney, 1998). In this study, we report the isolation of Pseudomonas aeruginosa in patients with active cases of otitis media. The recovery rate was $23.2 \%$, which is higher among males $(12.2 \%)$ than females $(11.0 \%)$. This is in agreement with the findings of Senuturia et al. (1958). Similar trends were reported by Ahmad et al., (1999). Contrary findings were reported by Loy et al., (2002) and Mansoor et al., (2009).

The rate of isolation was highest among patients within $0-14 \mathrm{yrs}$ age group $(11.0 \%)$ and least among patients within $>44 \mathrm{yrs}$ age group. The higher incidence among children could be attributed to the shorter, wider and horizontal eustachian tube in children than in adults, offering greater opportunities for pathogens to ascend 
from the nasopharynx to the sterile middle ear cavity (Stenfors and Raisanen, 1991).

Antimicrobial susceptibility tests revealed that Ciprofloxacin, Ofloxacin, and Peflacin were the most sensitive $(89.5 \%$ respectively). This concurs with the findings of Aslam et al., (2004) and Yismaw et al., (2010). High sensitivity was also observed against Ceporex and Streptomycin (79.0\% respectively). Nalidixic acid was the least sensitive and most resistant antimicrobial tested. Isolates were also resistant to Ampicillin and SulphamethoxazoleTrimethoprim. This is in agreement with the findings of Iseh and Adegbite (2004).

We hereby report the isolation of Pseudomonas aeruginosa from cases of suppurative otitis media, and hence, could play a role as a possible aetiologic agent of the disease. We have observed that isolates are more common among males than females, and mostly isolated from children aged 0-14yrs. Ciprofloxacin, Ofloxacin, and Peflacin, Ceporex and Streptomycin are hereby recommended for use in the treatment of otitis media caused by Pseudomonas aeruginosa.

Treatment should be done based on confirmed results of antimicrobial susceptibility tests, rather than empirical therapy. If antibiotics are started empirically, every effort should be made to obtain cultures and the choice of antibiotic used should be reviewed when the culture results are available.

\section{Acknowledgements}

The management of the University of Maiduguri is hereby acknowledged for giving us permission to conduct this study.

\section{References}

[1] Ahmad A, Usman J \& Hashim R, (1999) Isolates from chronic suppurative otitis media and their antimicrobial sensitivity in Pakistan. Armed Forces Medical Journal 49, 82-85

[2] Aslam M A, Ahmed Z, Azim R. (2004) Microbiology and drug sensitivity patterns of chronic suppurative otitis media. J Coll Physicians Surg Pak 14, 459-61

[3] Atlas R. M (1998). 'Microbiology fundamentals and applications (2nd edition). MacMillan publishing company, pp. 638-669

[4] Cowon S T \& Steel K J, (2002) Manual for the identification of medical bacteria (2nd Edition). Cambridge University Press, pp. 51-60

[5] Harold P. L. and Francis W. O. G (1992): Antibiotic and Chemotherapy (6th edition). Tim Home Edinburgh, London.

[6] Iseh K. R \& Adegbite T (2004) Pattern and bacteriology of acute suppurative otitis media in Sokoto, Nigeria. Annals of African Medicine 3:4, 164-166

[7] Lieberthal A.S, Carrol A. E, Chonmaitree T, Ganiats T. G, Hoberman A, Jackson M. A, Joffe M. D, Miller D. T, Rosenfield R. M, Sevilla X.D, Scwartz R. H, Thomas P. A and Tunkel D. E. (2013). 'The diagnosis and management of acute otitis media'. Paediatrics 133:2, 964-999 http://dx.doi.org/10.1542/peds.2012-3488.

[8] Loy A H C, Tan A L, Lu P K S (2002) Microbiology of chronic suppurative otitis media in Singapore. Singapore Med J 43, 296-9

[9] Lyczak J B, Cannon C L, Pier G B. (2000) Establishment of pseudomonas aeruginosa infection; lessons from a versatile opportunist. $\begin{array}{llll}\text { Microbes and Infection 2:9, } & 1051-1060\end{array}$ http://dx.doi.org/10.1016/S1286-4579(00)01259-4.

[10] Mackie T. J. and MacCartney J. E. (1998). Medical Microbiology; A Guide to Microbial Infections; Pathogenesis, Immunity, Laboratory Diagnosis and Control (15th Edition), pp. 175-464

[11] Tahira M., Mohammed A. M, Gulnaz K, Mustafa K. (2009) Pseudomonas aeruginosa in chronic suppurative otitis media: sensitivity spectrum against various antibiotics in Karachi. J Ayub Med Coll Abbottabad 2009 21:2, 120-123

[12] Udo, R.K. (1978). "A Comprehensive Geography of West Africa”. (1st edition). Heinemann Educational Books Nig. Ltd.

[13] Yismaw G, Abay S, Asrat D, Yifru S, Kassu A. (2010) A bacteriological profile and resistant patterns of clinical isolates from paediatric patients, Gondar University Teaching Hospital, Gondar Northwest Ethiopia. Ethiop. Med. J. 48:4, 293-300. 